\title{
FLORESTAN FERNANDES E A UNIVERSIDADE BRASILEIRA: UMA LEITURA DE RESISTÊNCIA
}

\section{FLORESTAN FERNANDES AND THE BRAZILIAN UNIVERSITY: A RESISTANCE READING}

Heriédna Cardoso Guimarães ${ }^{16}$

\begin{abstract}
Resumo
Este trabalho propõe, a partir do diálogo entre a obra sociológica e educacional de Florestan Fernandes e aspectos da realidade educacional brasileira, em especial os ataques à universidade brasileira na atualidade, a construção de uma leitura de resistência aos descaminhos propostos para o ensino superior no Brasil. Como primeiro momento apresento uma síntese do cenário educacional brasileiro, enfatizando os silenciamentos impostos ao campo educacional e sequencio com a justificativa para a escolha do intelectual, sociólogo e professor Florestan Fernandes. No bojo da ampla contribuição de Florestan destaco o livro "Universidade brasileira: reforma ou revolução?", os escritos acerca do padrão de escola superior brasileiro, como leituras propícias à compreensão e à construção de resistências aos retrocessos educacionais que estamos experienciando.
\end{abstract}

Palavras-chave: Universidade. Florestan Fernandes. Resistência.

\section{Abstract}

This paper proposes from the dialogue between the sociological and educational work of Florestan Fernandes, and aspects of the Brazilian educational reality, especially the attacks on the Brazilian university today, the construction of a reading of resistance to the proposals for higher education in Brazil. As a first moment, I present a synthesis of the Brazilian educational scenario, emphasizing the silences imposed on the educational field and following with the justification for the choice of the intellectual, sociologist and professor Florestan Fernandes. In the midst of Florestan broad contribution, I highlight the book "Brazilian University: Reform or Revolution?", The writings about the Brazilian higher school standard, as readings conducive to understanding and building resistance to the educational setbacks that we are experiencing.

Keywords: University. Florestan Fernandes. Resistance.

16 Programa de Pós-Graduação em Educação da Universidade Federal Fluminense. E-mail: heriedna@gmail.com. Telefone: (21)99862-9242. ORCID: http://orcid.org/0000-0003-0388-924X 


\section{RevistAleph}

\section{A universidade brasileira: uma utopia para muitos brasileiros}

A utopia está lá no horizonte. Me aproximo dois passos, ela se afasta dois passos. Caminho dez passos e o horizonte corre dez passos. Por mais que eu caminhe, jamais alcançarei. Para que serve a utopia? Serve para isso: para que eu não deixe de caminhar (BIRRI apud GALEANO, 1994).

Eduardo Galeano ao falar de uma ideia possível para a utopia propõe-nos, a partir da concepção de Fernando Birri, que é algo que "está lá", seguimos, mas quanto mais perto chegamos mais passos à frente ela está e assim seguimos caminhando rumo à utopia que nos alimenta subjetivamente. Bela e revigorante é a imagem do caminhar utópico, todavia, quando olhamos para o cenário educacional brasileiro que nós estamos vivenciando, em especial com o movimento político atual, a ideia de que uma educação pública, universal, laica e direito de todos os brasileiros/as aproxima-se mais de uma utopia como propõe Fernando e Galeano, do que de um direito conquistado e garantido.

Brasileiros e brasileiras são partes de heterotopias, espaços-tempos distintos que considerando as ideias de sociedade democrática e exercício da cidadania procuram construir um diálogo, em geral ou majoritariamente, via a política, entre a sociedade e o Estado. Entretanto, o diálogo, em especial os concernentes ao campo educacional e o Estado, em nosso passado recente e presente, ao que parece, já é utopia. Deveria acontecer, mas não acontece. Temos desde o ano 2017 mudanças que mais silenciam do que dialogam com uma educação pública, laica e direito de todos.

Exemplos diretos da ausência de diálogo encontramos no ensino médio via a promulgação da Lei № 13.415, de 16 de fevereiro de 2017 - antiga Medida Provisória $\mathrm{n}^{\circ}$ 746/ 2016 - que altera diferentes artigos da LDB/1996 - Lei de Diretrizes e Bases da Educação Nacional Lei $n^{\circ}$ 9.394, de 20 de dezembro de 1996 -. As alterações no texto da LDB/1996 se concentram mais no Capítulo II que trata da Educação Básica, nos: Artigos 24, 26; com a inserção do Artigo 35 A na Seção IV que trata do Ensino Médio, colocando a Base Nacional Comum Curricular (BNCC) como definidora/ norteadora dos "direitos e objetivos de aprendizagem do ensino médio" (BRASIL, 1996, s/p); na modificação do Artigo 36 atrelando totalmente o currículo do ensino médio à BNCC e inserindo os quatro "itinerários formativos", devendo estes serem "organizados por meio da oferta de diferentes arranjos curriculares, conforme a relevância para o contexto local e a possibilidade dos sistemas de ensino, a saber" (BRASIL, 19996, sp). 


\section{RevistAleph}

As modificações estendem-se ao Capítulo IV, que trata da Educação Superior, em seu Artigo 44, Inciso IV, submetendo os processos seletivos de acesso ao ensino superior as competências e as habilidades definidas na BNCC e por fim, mas não menos importante, altera o Título VI que trata do profissionais da educação, em seus Artigo 61, Incisos IV e V, incluindo os profissionais com notório saber, e Artigo 62, parágrafo oitavo, que coloca a Base Nacional Comum Curricular como referência curricular para os currículos dos cursos de licenciatura de todo país. Essas mudanças, em especial as concernentes aos profissionais da educação e aos currículos dos cursos de licenciatura limitados pela BNCC, enfraquecem o reconhecimento do exercício docente como uma profissão que necessita de formação específica, que possui características sui generis, e incita os professores a vivenciarem uma disputa insana por espaços de trabalho cada vez mais precários, sendo, a precarização dos espaços-tempos do exercício docente e da própria ideia de escola e de universidade, um dos motivos para a inserção e adesão densa por parte do governo ao mercado educacional e as parcerias público-privadas.

No conjunto dos exemplos que cerceiam o diálogo entre os sujeitos que constroem a educação brasileira e o Estado temos o Projeto Escola Sem Partido (PL 7.180/14), também conhecido como lei da mordaça. O site do Movimento Escola Sem Partido (PARTIDO, 2019, $s / p)$, propositor do projeto acima mencionado, sinaliza que um dos motivos para a implementação deste projeto é a construção de "uma sociedade mais justa" ou do combate ao preconceito e justifica esta proposição a partir da afirmação de que professores de todos os níveis vêm utilizando o tempo precioso de suas aulas para "fazer a cabeça" dos alunos sobre questões de natureza político-partidária, ideológica e moral. Há também, relativo a este projeto, no texto do Anteprojeto de Lei Federal e Minuta de Justificação - ESP versão 2.0 - justificativas para a descrição dos novos "deveres dos professores". Dentre estes destaco o "dever" docente de aquiescer à gravação de suas aulas sob o argumento da "garantia de padrão de qualidade", pois, como exposto no site:

O projeto reconhece também o direito dos estudantes e dos pais de gravar as aulas, caso a escola não o faça ou não disponibilize as gravações. Tratase de direito que decorre do artigo 206, VII, da Constituição - que assegura, entre os princípios com base nos quais o ensino será ministrado, a "garantia de padrão de qualidade" - o que implica necessariamente para os pais o direito de conhecer e avaliar a qualidade dos serviços prestados pelas escolas -; e do artigo 53, par. único, do ECA, que reconhece aos pais o direito de ter ciência do processo pedagógico vivenciado por seus filhos (PARTIDO, 2019, s/p). 


\section{RevistAleph}

Interessante observar que no contexto das profissões liberais mais reconhecidas no Brasil, óbvio que a categoria docente não está incluída neste campo - considerando todas as discussões que envolvem a profissionalização docente e o nosso espaço de ação historicamente construído, aproximamos mais de proletários do que de profissionais liberais; a tendência ao proletariado é a garantia de perda da autonomia sobre a construção do processo, o que já está sendo realizado com o projeto escola sem partido -, tal proposição seria absurda, haja vista que o "padrão de qualidade" dos serviços prestados é normatizado via conselhos nacionais e não pelo senso comum dos clientes, leia-se no contexto educacional, os pais e alunos.

Ampliando os elementos do conjunto silenciamento da educação brasileira temos: a sugestão de regulamentação do ensino domiciliar via medida provisória (BOND, 2019, s/p); a declaração do ex-ministro da Educação, Ricardo Vélez Rodriguez de que "as universidades devem ficar reservadas para uma elite intelectual, que não é a mesma elite econômica" (FOCO, 2019, s/p); a rejeição em cinco Instituições de Ensino Superior (IES) do primeiro nome indicado na lista tríplice para o cargo de reitor e a indicação em duas IES de nomes que não compunham a lista tríplice, ferindo a autonomia universitária. Importante sinalizar que no dia 24 de dezembro de 2019 foi publicada no Diário Oficial da União Edição extra - o texto da Medida Provisória n 914, que dispõe sobre o processo de escolha dos dirigentes das universidades federais, dos institutos federais e do Colégio Pedro II. Além de indicar os meios legais para a organização do processo de construção da lista tríplice a MP n 914/2019 em seu Art. 60 determina que o "reitor será escolhido e nomeado pelo Presidente da República entre os três candidatos com maior percentual de votação" (BRASIL, 2019, s/p). E, mais recentemente, a proposta-lei que institui o Programa Institutos e Universidades Empreendedoras e Inovadoras - FUTURE-SE, que é um projeto do Ministério da Educação divulgado pelo atual ministro Abraham Weintraub e pelo secretário de Educação Superior, Arnaldo Lima, no dia 16 de julho de 2019.

O texto, minuta não oficial (BRASIL, 2019), da proposta do Future-se apresenta os três eixos norteadores do programa - 1) Gestão, Governança e Empreendedorismo; 2) Pesquisa e Inovação; 3) Internacionalização - como a solução para o alcance da "autonomia administrativa e financeira" e, consequentemente, a diminuição, ou liberação total do Estado, de compromissos relativos à manutenção financeira das Instituições de Ensino Superior (IES). Outra consequência é a adesão total do campo educacional, em seus 


\section{RevistAleph}

diferentes níveis, ao mercado; as IES serão empresas. $\mathrm{O}$ alcance da autonomia financeira das IES proposto pelo Future-se terá como preço a perda da autonomia na realização de pesquisas que contemplem elementos da extensão universitária, aspectos locais e comunitários, pois, como disposto no Artigo $2^{\circ}$, ao aderir ao FUTURE-SE, as IFES se comprometem a "utilizar a organização social contratada para o suporte à execução de atividades relacionadas aos eixos previstos" (BRASIL, 2019, s/p), de modo que as metas e objetivos sejam atendidos. As organizações sociais terão a liberdade para escolher, seguindo o argumento de atender os três eixos norteadores, projetos que possam verter em lucro - leia-se, investir em pesquisas que tenham alto potencial de retorno lucrativo, seja via o registro de patentes, vendas diretas de serviços e negociação destas com o mercado direto.

O Artigo 17 é translúcido nesse sentido ao dispor acerca dos deveres das organizações sociais (OS), que são:

[...] I - buscar a implementação da Lei 13.243, de 2016, aumentando a interação com o setor empresarial, no intuito de contribuir com a capacidade inovadora do setor e atender as demandas do setor empresarial por inovação; II - aprimorar as atividades de pesquisa, desenvolvimento e inovação, de nível nacional e internacional, buscando disseminar a cultura da inovação, da propriedade intelectual e da transferência de tecnologia; III - potencializar e difundir o papel das IFES nas atividades de cooperação com os setores público e privado; IV - atrair a instalação de centros de pesquisa, desenvolvimento e inovação (P,D \& I) nas IFES; $V$ - fortalecer os Núcleos de Inovação Tecnológica (NIT), nos institutos e universidades federais; $\mathrm{VI}$ - facilitar a realização de projetos de pesquisa e desenvolvimento, conjuntamente com universidades estrangeiras, incluindo projetos que incluam empresas brasileiras e estrangeiras nos projetos de P,D\&I; VII - promover a contínua interação entre empresas e IFES aptas a produzir pesquisa e desenvolvimento e inovação (BRASIL, 2019, s/p).

O dever mais importante das OSs será fazer o marketing empresarial das IES; a adesão ao Future-se é sinônimo de afastamento da tríade ensino-pesquisa-extensão que norteia a construção da universidade brasileira, sem mencionar os impactos internos entre os docentes efetivos que prestam serviço à OS e docentes contratados, estudantes de graduação e pós-graduação, e disputas por representações de poder possibilitadas pelo ranqueamento gerado pelo e com o marketing empresarial.

Este cenário, delineado pelo conjunto de exemplos de silenciamentos que ratificam a ausência de diálogo entre o Estado e o campo educacional brasileiro, assim 


\section{RevistAleph}

como, o corte no orçamento das IES, os cortes de bolsas da pós-graduação, encaminha-nos a uma ideia de educação pública, laica, universal e direito de todos, e em especial de uma educação superior pública como utopia. A universidade brasileira estará lá, mas permanecerá lá, distante e intocável para a maioria dos brasileiros/as.

Considerando, que a utopia é um alento, mas não o suficiente; que a universidade brasileira é "um todo que agrega uma diversidade de campos do saber, ou seja, uma unidade na diversidade" (PAULA, 2003, p. 53), que não pode ser como O castelo de Franz Kafka, e nós, não devemos ser funcionários do castelo, nem o agrimensor, é possível, a partir da leitura sociológica e educacional construída por Florestan Fernandes, em especial a concentrada na obra Universidade brasileira: reforma ou revolução - publicado em 1968 em meio ao período ditatorial, espaço-tempo signo do silêncio para as universidades encontrar ecos e ideias que nos auxiliem a pensar a atual universidade brasileira que temos e, talvez, construir pontos de resistência em meio aos caminhos que o cenário político nos apresenta.

\section{Florestan Fernandes e sua leitura para o Brasil conservador de seu/nosso tempo}

A escolha pelo nome Florestan Fernandes não é ingênua e se justifica por sua rica produção para o campo educacional mesmo ele não se considerando um educador. Para o professor, sociólogo e intelectual Florestan Fernandes “a Educação, quando não é esmagada pela ignorância, é esmagada pela escassez de recursos" (BRASIL, 1991, p. 37) e se olharmos para os cortes que a educação vem sofrendo na atualidade brasileira essa fala que foi realizada no início dos anos noventa (1991) ganha contornos densos de tempo presente. Para ele, precisamos ser mais radicais, pois não basta libertar os oprimidos, precisamos incorporar os excluídos e esta é uma das principais funções das universidades, "a de levar o conhecimento mais avançado àqueles que não tiveram a oportunidade de aprender, àqueles que foram expulsos" (BRASIL, 1991, p. 47).

No discurso apresentado no projeto "Memória Viva da Educação Brasileira" (BRASIL, 1991), iniciado pelo INEP em 1989, Florestan fala sobre a necessidade de cultura para a vida do trabalhador, pois este

[...] tem tanta necessidade de cultura quanto aquele que não é trabalhador, aquele que é proprietário dos meios de produção. Por que os 


\section{RevistAleph}

que são proprietários dos meios de produção têm capacidade de comandar, a arrogância de mandar etc.? Porque eles aprendem nas escolas uma educação de classe e adquirem uma cultura geral que é uma cultura formativa. Temos de dar ao trabalhador essa mesma Educação. $\mathrm{O}$ educador precisa conhecer o mundo, explicar o mundo, transformar o mundo e, para isso, não basta dar ao trabalhador adestramento na situação de trabalho, a escolaridade técnica. Ele precisa, inclusive, se possível, percorrer todos os graus de ensino (BRASIL, 1991, p. 49).

Nesse mesmo discurso ele nos alerta sobre o caráter salvacionista e diretivo que nós imprimimos às leis e, consequentemente, sobre a nossa realidade e nos pede para

[...] fazer um esforço que transcenda à ideia de lei. Se nós nos prendermos muito, como legisladores, à ideia de lei, nós vamos acabar caindo numa cilada, que é velha no Brasil. A lei sempre foi um instrumento dos poderosos, dos que mandam. E os que mandam nunca instituem normas que aumentem o poder dos que são mandados. Criam normas que aumentem o seu próprio poder, sua capacidade de comando. E se nós queremos igualdade, liberdade, solidariedade humana, humanização da pessoa, não-objetificação e não-brutalização da pessoa, nós temos de mudar o eixo do sistema educacional (BRASIL, 1991, p. 57).

Elencar diferentes falas e/ou ideias construídas e apresentadas pelo professor Florestan ao longo de sua vida e que ecoam com diferentes contextos próximos a nós é só um dos modos de ratificar a escolha pelo seu nome, mas que não se esgota. A ideia de que o professor e sociólogo Florestan também era um intelectual é parte dos motivos para a escolha, em especial para tempos sombrios, pois, os 'homens de cultura' podem suscitar caminhos e descaminhos, sejam eles de viés ideológicos (ideólogos), expert (técnicos), ou ambos.

Octávio lanni, na ocasião de sua participação no "Seminário Itinerante: dependência econômica e cultural, desenvolvimento nacional e formação de professores" (CATANI et.al, 1987), realizado na USP no ano 1985, questiona o papel das universidades na formação dos intelectuais, com destaque para o olhar de que o professor, em especial o professor universitário, "em se formando na Universidade e entrando na vida, 'caindo na vida', como se diz na gíria, é um intelectual que entra no jogo das forças sociais. Entra no jogo do poder e, é claro, das forças sociais" (IANNI, 1987, p. 48). A fala de lanni, historicamente contextualizada, remete a um período pós ditadura militar, a uma universidade pós Reforma Universitária de 1968, que precisa olhar para si, repensar novos rumos para formação intelectual e cultural brasileira, para a ciência em nosso país, afinal, o discurso ressonante no período ditatorial foi de que, um país subdesenvolvido como o Brasil 


\section{RevistAleph}

não precisa realizar pesquisa original ou "dedicar-se a uma atividade intelectual mais criativa, porque isso os países mais desenvolvidos" (IANNI, 1987, p. 41) já faziam muito bem.

A herança que temos não se reduz a uma dependência econômica, mas também a uma sujeição cultural, social e, portanto, intelectual, logo, pensar o(s) intelectual(is) no contexto brasileiro é muito importante e Florestan Fernandes é um exemplo emblemático desse intelectual. Sua formação de sociólogo, professor universitário da USP, aposentado via Ato Institucional no período da ditadura, político, publicista e defensor de uma educação pública e de um país democrático, não ficam a desejar neste sentido.

Acerca do conceito de intelectual é importante sinalizar que não há uma única leitura. A relação entre os intelectuais, a política, e o poder possui sua própria história e movimento que se localizam "no cruzamento das histórias política, social e cultural" (SIRINELLI, 2003, p. 232) dos Estados, nações, sociedades e fabricam um caráter polissêmico para o conceito. Norberto Bobbio (1997) coloca que atualmente chama-se de intelectual aqueles homens que em outros tempos eram os homens de cultura, os sábios, doutos, filósofos, literatos, entre outros, que propagavam a verdade via princípios morais e éticos, oscilando entre o programa filosófico da república platônica e a crítica filosófica do século XVIII. Os intelectuais, independente da denominação ou rótulo, sempre existiram, pois onde há poder político, poder econômico, há poder ideológico e este é majoritariamente o campo de ação dos intelectuais.

O poder ideológico é extremamente dependente da natureza do homem como animal falante. Toda sociedade tem os seus detentores do poder ideológico, cuja função muda de sociedade para sociedade, de época para época, cambiantes sendo também as relações, ora de contraposição, ora de aliança, que eles mantêm com os demais poderes (BOBBIO, 1997, p 11).

Paralela a existência do intelectual há a discussão sobre a função do intelectual, e esta, retoma aspectos como a diferenciação entre a "prescrição" e a "descrição". Neste cenário, encontramos proposições como a de Benda, que enxerga a tarefa do intelectual como não política, mas iminentemente espiritual; Mannhein, considera a tarefa intelectual como teórica, porém, essa acaba sendo política porque é do intelectual a função de realizar a síntese ideológica que dá "passagem" as futuras ações políticas; Ortega, agrega à tarefa do intelectual a "função de educar as massas" e, portanto, é tarefa teórica e política; Croce, propõe que é uma tarefa política, todavia, esta política não é "a política ordinária dos governantes, mas a da cultura" (BOBBIO, 1997, p. 34), específica e adaptada ao contexto 


\section{RevistAleph}

social do momento; Norberto Bobbio (1997, p. 77), sinaliza que a sua conduta ideal, se for possível assim pensar, para o intelectual é a de uma "independência na indiferença", é participar das lutas políticas, porém, sem deixar alienar-se a ponto de ligar-se a uma palavra de ordem, a ponto de perder a capacidade crítica para os rumos do movimento; e Gramsci, olha o intelectual como produto de sua classe, segue o olhar histórico de Mannhein, mas refuta sua ideia de livre intelligentsia (base para o intelectual autônomo) apresentando a separação entre intelectual tradicional e intelectual orgânico. Para Gramsci,

[..] todo grupo social ... nascendo no terreno originário de uma função essencial no mundo da produção econômica, cria para si, ao mesmo tempo, de um modo orgânico, uma ou mais camadas de intelectuais que Ihe dão homogeneidade e consciência da própria função (BOBBIO, 1997, p. 131).

Desse modo, Gramsci ratifica a não dissociação entre engajamento político e engajamento cultural; o intelectual é especialista (técnico) e político [especialista + político]. É a partir dessa leitura gramsciana para a função do intelectual que Octávio lanni considera o professor como intelectual orgânico e que Florestan Fernandes constrói seu olhar sociológico para o Brasil e defende a educação pública e uma universidade brasileira digna desse nome. Para Florestan, a partir de sua posição como intelectual socialista, a relação teoria e prática é indissolúvel, não tem como separar o professor de seu olhar político e nem a educação de sua dimensão política, social e econômica.

Nas palavras de Florestan, é tarefa do educador brasileiro [...] preparar
personalidades democráticas para uma ordem social democrática, e que
(atenda a) certos fins práticos, com o desenvolvimento da consciência de
afiliação nacional e dos direitos e dos deveres do cidadão, de uma ética de
responsabilidade, de capacidade de julgamento autônomo de pessoas,
valores e movimentos sociais (FERNANDES apud MATUI, 2001, p. 63). O
professor não pode estar alheio a essa dimensão. E, o que é muito mais
importante, se ele se colocar do lado da mudança, terá que realizá-la em
dois níveis - dentro e fora da escola. Ao seu papel de educador terá que
fundir o seu papel de cidadão (OLIVEIRA, 2005, p. 173, destaque do autor).

Retomando as justificativas para a escolha do nome Florestan, é no âmbito de sua produção sociológica que encontramos um olhar para a formação da sociedade brasileira e sua construção; o olhar sociológico construído por Florestan remete à ideia de um Brasil que experiencia na pele, de forma densa, um capitalismo dependente que têm como principal, entre as diversas consequências, uma sociedade que orbita em torno de uma heteronomia cultural, social e econômica. Desse modo, olhar e analisar as posições e ações 


\section{RevistAleph}

da burguesia brasileira, produto do modelo econômico capitalista dependente é fundamental, pois, o próprio capitalismo em si já gera lucro, acúmulo de riqueza, crescimento da desigualdade social, alto número de assalariados e predomínio de propriedades privadas, além da pouca intervenção econômica do Estado, e, a burguesia local, no caso dos países que estão condicionados à condição de capitalismo dependente como o Brasil, executam um papel fundamental que é a realização de mudanças para que a condição dependente permaneça.

A heteronomia é naturalizada e ratificada pela burguesia conservadora brasileira nos diferentes espaços, sentidos e instituições, de modo que, além da apropriação e expropriação inerentes ao modelo capitalista a classe burguesa brasileira impõe, implementa e desenvolve sobre apropriação e a sobre expropriação capitalista sobre corpos e mentes do proletário brasileiro.

O capitalismo dependente repercute de modo direto nas políticas educacionais, em especial por meio da conformação de uma base produtiva que não pode possuir centros estratégicos de inovação tecnológica e, consequentemente, não demanda de modo significativo mão-de-obra com elevada formação acadêmica. Isso ocorre em virtude da natureza mesma dessa dependência fundamental. Conforme Cardoso (1997), o conceito de capitalismo dependente: a) implica, na verdade, relações de dominação que se conjugam: dominação externa e dominação interna. Dominação externa que é abastecida pela dominação interna, a qual se exerce não sobre um setor ou uma fração da burguesia, mas sobre o trabalho e a massa da população (LEHER, 2007, p. 10).

As repercussões sobre a educação brasileira ficam claras quando observamos a história das universidades brasileiras e aspectos da economia. Não é tema deste texto a leitura de ações econômicas que ratificam o olhar de Florestan, todavia, acontecimentos recentes em nosso país saltam, mesmo que sob interpretação baseada no senso comum. No que se refere a educação, é muito importante pensar que a dependência cultural criada pela condição de capitalismo dependente e adensada via a heteronomia cultural possui raízes profundas e quase invisíveis, ou melhor esquecidas; as escolas superiores foram exemplo de uma condição subserviente a uma dependência cultural. Uma escola voltada para si mesma e dedicada a formação de profissionais liberais fruto da burguesia brasileira. O ensino médio sem identidade com o mercado de trabalho e muito aquém de uma formação cultural de classe; a criação de uma universidade particular em cada esquina das cidades. 


\section{RevistAleph}

Para Florestan, o problema não é utilizar os valores, interesses ou conhecimentos externos, sejam europeus ou dos Estados Unidos, como instrumentos de análise para se pensar a ausência de autonomia ou a possibilidade de construção de uma condição intelectual autônoma perante as culturas europeias e americanas, mas, sim, não nos atentarmos às "maneiras de interligá-los" à nossa cultura, de modo que não internalizemos "valores e disposições subjetivas de núcleos civilizatórios que nos dominam. Esta é uma forma de domínio (cultural), que é fortalecedora do outro lado deste mesmo domínio (econômico)" (CARDOSO, 1996, p. 106).

Lamentavelmente, a realidade que nos salta aos olhos é a de que um momento de descuido ou, pode-se dizer, uma negligência consentida, aconteceu no passado sob o signo desenvolvimentista a todo custo e permanece, haja vista, que temos 12,8 milhões de desempregados (GARCIA, 2019, s/p), um aumento de $25 \%$ no número de população subocupada, uma reforma da previdência que silencia os direitos trabalhistas, a indução para a extinção de agências de fomento de pesquisa, a tentativa de entrega das universidades as administradoras, sendo, tudo isso natural para uma nação que está em crescimento (sic). O crescimento é mais no campo do desconhecimento do que na economia; é realmente a naturalização de uma cultura e modelo societal externo que não cabe nos trópicos que vivemos. A educação nesse cenário está subjugada à condição de aparelho de reprodução e ampliação ideológica do Estado, mas o Estado brasileiro, historicamente, atende primeiro aos propósitos da burguesia brasileira e por isso a educação das massas sofre sanções quando busca não reproduzir totalmente os ditames culturais externos e pseudo desenvolvimentistas. É, conscientes dessa realidade educacional, pautada na ausência de diálogo e na criação de sanções, que a leitura do livro Universidade Brasileira: reforma ou revolução?, destacando temas comuns à maioria dos capítulos, auxilia-nos a pensar acerca de aspectos que tem tornado a educação brasileira pública, laica e democrática uma utopia.

\section{O livro - Universidade brasileira: reforma ou revolução?}

Universidade brasileira: reforma ou revolução? - é um livro construído a partir de conferências realizadas por Florestan Fernandes nos anos 1967 e 1968, "no contexto da discussão das reformas de base ou reformas de estrutura" (FERNANDES, 1979, p. vii) para 


\section{RevistAleph}

a universidade e como tentativa de resistência à perda do espaço político para o regime ditatorial. Florestan coloca no prefácio da segunda edição que esse livro é uma obra menor na sua produção intelectual, todavia, sua relevância e atualidade não se deve ao dados quantitativos que apresenta sobre a universidade, número de matrícula, de concluintes, de cursos oferecidos, no fim dos dos anos sessenta, mas sim, à sua potência reflexiva no que se refere ao alerta de que ações ou reformas que sigam ideias conservadoras recaem na manutenção de antigos e consolidados estereótipos institucionais e sociais, relembrandonos, que nem toda mudança é no sentido positivo.

O livro está organizado em duas partes, a primeira - O diagnóstico da situação com cinco capítulos e a segunda - Os sentidos da "Reforma Universitária" - com quatro capítulos. Os cinco capítulos iniciais versam entre dados quantitativos sobre a universidade brasileira dos anos finais da década de 1970, a diferenciação entre escolas superiores e universidades, a discussão sobre a relação entre universidade e desenvolvimento e a gratuidade no Ensino Superior, ampliando o olhar para a gratuidade do ensino como privilégio social. Os quatro capítulos da segunda parte discutem a reforma universitária e mudança social, a reforma consentida, o caso da Universidade de São Paulo e a relação entre universidade e pesquisa. O último texto do livro é um apêndice - A universidade ambígua -; este texto é uma resenha crítica escrita por Florestan sobre o livro $A$ universidade necessária de Darcy Ribeiro.

Ao longo destes dez textos os temas Escola Superior e desenvolvimento, ambos associados à universidade, são recorrentes. O padrão brasileiro de Escola Superior aparece em diferentes partes do livro, pois como propõe Florestan, não é possível "explicar como surgiu esse padrão" (FERNANDES, 1979, p. 55.), mas para pensarmos a universidade brasileira é necessário compreender as consequências deste padrão e até abandoná-lo.

A escola superior brasileira constituiu-se como uma escola de elites culturais ralas e que apenas podiam (ou sentiam necessidade social de) explorar o ensino superior em direções muito limitadas como a massa de conhecimentos procedia do exterior e a sociedade só valorizava a formação de profissionais liberais, a escola superior tornou-se uma escola de elites, de ensino magistral e unifuncional: cabia-lhe ser uma escola de transmissão dogmática de conhecimentos nas áreas do saber técnicoprofissional, valorizadas econômica, social e culturalmente pelos estratos dominantes de uma sociedade de castas e estamental (FERNANDES, 1979, p. 55-56). 


\section{RevistAleph}

As Escolas Superiores não foram instituições com grande corpo técnico ou orçamento livre, foram também reféns de uma sociedade de classes que considera a educação como privilégio, e, portanto, distante da maioria da população. A dedicação da escola superior às profissões liberais para antes de ser o reflexo do conservadorismo da burguesia brasileira era também um modo de não tornar a educação, o exercício docente, um meio de ação econômico e socialmente aceitável, pois o advogado, o engenheiro, o médico priorizava as demandas dos escritórios para depois atender as atividades docentes nas escolas superiores e universidades conglomeradas. A cátedra centralizava as possibilidades de barganha do conhecimento e da produção científica que era possível. Uma vez obsoleta a estrutura das escolas superiores e a realização das reformas no Governo Castelo Branco (reformas no papel) a cátedra abre espaço para os departamentos e institutos, o que não significa abertura para uma universidade que se preocupa com a produção científica que modifique a condição intelectual dependente que nos perpassa. A herança colonizadora, escravocrata e da primeira república quando ressignificadas pelo desenvolvimentismo e pelo movimento ditatorial não foi modificada em seu cerne, mas, sim, reconfigurada em um modelo educacional onde o público e o privado coexistem e não produzem uma ideia de educação para todos dotada de sentido claro.

No bojo da ausência de sentido busca-se uma educação para o desenvolvimento e uma universidade inventiva que possibilite tal feito, inclusive via a autonomia financeira leia-se, future-se -; todavia, como coloca Florestan, a construção de uma universidade multifuncional e integrada - deste tipo requer uma desalienação cultural, de modo que "por trás desse tipo de instituição [...] está a passagem de um estado de dependência cultural relativa para um estado de autonomia cultural relativa" (FERNANDES, 1979, p. 85). A autonomia cultural relativa e, portanto, universitária, requer o diálogo fluente com o externo, mas não na condição difusionista, e sim com a produção original de saber nos campi universitários, e via o controle que parte de dentro e não é imposto de fora.

Concomitante à necessidade de mudança no campo subjetivo nacional temos a questão do financiamento das universidades. Como manter a mudança? Florestan deixa claro que "sem o mínimo de recursos em uma escala constante ou crescente de progressão, o Brasil nunca produzirá uma mentalidade educacional média e conhecimentos científicos ou tecnológicos para lutar contra os efeitos adversos do subdesenvolvimento" (FERNANDES, 1979, p. 92) e superar a condição dependente. Uma opção é a fixação de 


\section{RevistAleph}

alíquotas sobre algumas rendas do Estado, ou a criação de um imposto especial para a educação; a participação privada, a cobrança de mensalidades, não resolve o problema de financiamento de uma universidade para o desenvolvimento. É necessário a opção por uma educação democrática em todos os sentidos e níveis, e esta precisa ser iniciada pela classe burguesa brasileira. Esta opção não é do Estado, pois este reproduz a ideologia desta classe conservadora, que ratifica e amplia a desigualdade, que carrega traços densos de preconceito escravocrata e cultural, haja vista, que não aceita a pluralidade cultural, social, econômica e de nação que é o Brasil. O truncamento educacional que experienciamos é só uma das diferentes formas de ação para manter o status da classe burguesa, afinal, mesmo tendo a construção do apartheid educacional nos governos dos anos 2000 é difícil aceitar que os campi universitários são plurais como a nação brasileira.

\section{Olhares que tentam resistir...}

A reforma universitária de 1968 foi a reforma do silêncio, da docilidade dos corpos, do arrefecimento da capacidade de luta da categoria docente e dos estudantes. Florestan, "ao revés de Paulo Prado", escreve que

[..] numa terra radiosa, vive um povo alegre em eterna servidão. A reforma universitária não nos libertará dessa servidão. Mas nos poderá ensinar os caminhos intelectuais e políticos que permitirão conquistar a própria liberdade intelectual e política, condição moral para extinguir todas as formas de servidão, internas e externas, que metamorfoseiam uma terra radiosa e um povo alegre numa realidade triste (FERNANDES, 1979, p. xxii).

Parafraseando Florestan, cabe-nos perguntar: o Future-se é um programa que poderá nos ensinar os caminhos intelectuais e políticos que permitirão conquistar a própria liberdade intelectual e política dentro e fora das universidades? Pelo exposto no decorrer deste texto é possível dizer que não. Entretanto, não podemos deixar que a universidade pública, totalmente gratuita, laica e democrática seja perdida antes mesmo de ser conquistada; é urgente que pensemos pontos de resistência, não só para os ataques a ela direcionado, mas contra todos os modos de silenciamento que a educação brasileira vem sofrendo.

Florestan nos alerta que as leis organizadas e sancionadas em países que vivem sob a experiência de heteronomia cultural, moral, social e econômica como o nosso Brasil, uma 


\section{RevistAleph}

heteronomia intensa e acrítica, são leis organizadas e sancionadas pela classe burguesa e esta não vai ampliar e melhorar a qualidade e o acesso à educação para as massas, para a maioria da população. Essas leis tendem a ampliar as desigualdades sociais e ratificar os estereótipos meritocráticos que em nada correspondem à realidade de nosso país, não há mérito quando não há condições democráticas de acesso, permanência e construção de estabilidade a longo prazo.

Outro alerta de Florestan, que passa despercebido, mas é muito atual e importante, está relacionado à construção histórica do modelo de universidade brasileira e suas mudanças para permanecer como era. Ao discutir a mudança como uma possibilidade de afastamento do sinônimo de progresso, de evolução e crescimento, Florestan apresenta a possibilidade de olharmos a mudança como uma maquiagem contextual e momentânea e por isso não dialógica com o contexto social que a rodeia, sendo este, o destino das universidades a partir da adesão ao Programa Future-se; o future-se é o 'novo', a 'mudança', que traz para a universidade multifacetada que temos o antigo padrão de escola superior brasileiro, onde o profissional liberal dá aulas de vez em quando e não se assume professor em uma sociedade dependente cultural e social como a nossa.

É caracterizada como pioneiro na obra sociológica de Florestan a construção e produção de uma sociologia brasileira, voltada para os brasileiros e que foi realizada a partir e com o espaço universitário que ele dispunha. Este legado não pode ser perdido, e mais importante, este modo de pensar a relação entre a universidade e a sociedade não poder ser silenciado, por mais que forças militares e paramilitares trabalhem para tal. Entregar as universidades e seu fazer intelectual ao mercado, à subserviência do capital neoliberal no sentido acrítico total é admitir a derrota e a naturalização de que somos incapazes de construir uma rede de produção e diálogo científico autônomo, é naturalizar que as desigualdades e singularidades que o território brasileiro compõem são invisíveis e silenciáveis via a exclusão daqueles que nunca foram parte da nação higienizada pela colonização.

Fiquemos atentos e críticos à exclusão que a economia e a educação brasileira estão fazendo e ampliando no território, pois, a universidade pública e laica, que deveria ser um dos polos da crítica, está sendo sucateada e silenciada por dentro via o programa Future-se, o Projeto Escola Sem Partido, entre outros que são mantidos e idealizados por intelectuais brasileiros que servem a lógica conservadora de sua classe, a classe burguesa 


\section{RevistAleph}

brasileira, que ao contrário da europeia não admitiu que o cidadão que sofre a expropriação maciça de sua força de trabalho precisa ter acesso à educação, saúde, cultura para sobreviver como sujeito/indivíduo que trabalha e consome.

\section{Referências}

BOBBIO, Norberto. Os intelectuais e o poder: dúvidas e opções dos homens de cultura na sociedade contemporânea; tradução de Marco Aurélio Nogueira. São Paulo: Editora da Universidade Estadual Paulista, 1997.

BOND, Letycia. MP do ensino domiciliar deve ser editada até 15 de fevereiro, publicada em 06 fevereiro 2019. Agência Brasil - Brasília, s/p, 2019. Disponível em http://agenciabrasil.ebc.com.br/educacao/noticia/2019-02/mp-do-ensino-domiciliar-deve-sereditada-ate-15-de-fevereiro. Acesso em 23 agosto 2019.

BRASIL. Medida Provisória № 914, de 24 de dezembro de 2019. Dispõe sobre o processo de escolha dos dirigentes das universidades federais, dos institutos federais e do Colégio Pedro II. Diário Oficial da União - Edição Extra, publicado em 24 de dezembro 2019. Disponível em http://www.planalto.gov.br/ccivil_03/_ato2019-2022/2019/Mpv/mpv914.htm. Acesso em 13 abril 2020.

BRASIL. Programa Institutos e Universidades Empreendedoras e Inovadoras - FUTURE-SE. 2019. Disponível em: https://www.cgee.org.br/documents/10195/734063/Programa+Futurese/c762b108-c424-4b03-8bee-f521e7c5e3f0?version=1.0. Acesso realizado em 25 agosto 2019.

BRASIL. Lei № 9.394, DE 20 DE DEZEMBRO DE 1996, que estabelece as diretrizes e bases da educação nacional. Diário Oficial da União, publicado em 23 dezembro de 1996. Disponível em http://www.planalto.gov.br/ccivil_03/leis/19394.htm. Acesso em 13 de abril 2020.

BRASIL. Florestan Fernandes. Brasília, MEC/INEP, 1991. (Coleção Memória Viva da Educação Brasileira, v. 1).

CARDOSO, Miriam Limoeiro. Capitalismo dependente, autocracia burguesa e revolução social em Florestan Fernandes. Idéias (Revista do Instituto de Filosofia e Ciências Humanas da Unicamp). Campinas, v. 4, n. 1-2, p. 99-1 14, 1997

CARDOSO, Miriam Limoeiro. Florestan Fernandes: a criação de uma problemática. Estudos Avançados, v. 10, n. 26, pp. 89-128, 1996. Disponível em: http://www.scielo.br/scielo.php?script=sci_abstract\&pid=S0103-

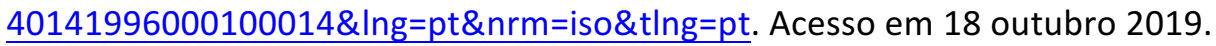

CATANI, Denice Bárbara; MIRANDA, Hercília Tavares de; MENEZES, Luís Carlos de; FISCHMANN, Roseli. Universidade, escola e formação de professores. - São Paulo: Editora Brasiliense, $2^{\circ}$ ed., 1987.

FERNANDES, Florestan. Universidade brasileira: reforma ou revolução? 2. Ed. São Paulo: AlfaOmega, 1979. 


\section{RevistAleph}

FOCO, Congresso. Universidade "não é para todos", mas "somente para algumas pessoas", diz ministro da Educação, publicada em 30 janeiro 2019. Site Congresso em Foco. Disponível em https://congressoemfoco.uol.com.br/educacao/universidade-nao-e-para-todos-mas-somentepara-algumas-pessoas-diz-ministro-da-educacao/ . Acesso em 24 agosto 2019.

GALEANO, Eduardo. Las palabras andantes? Siglo XXI, 1994. Extraído de https://www.revistaprosaversoearte.com/para-que-serve-a-utopia-eduardo-galeano/ . Acesso em 13 outubro 2019.

GARCIA, Diego. Desemprego cai, mas renda média diminui e crescem trabalhadores informais, publicada em 31 julho 2019. Site Folha de São Paulo. Disponível em https://www1.folha.uol.com.br/mercado/2019/07/taxa-de-desemprego-cai-e-fica-em-12-nosegundo-trimestre-de2019.shtml\#targetText=|BGE\%20diz\%20que\%2012\%2C8,trabalhadores\%20n\%C3\%A30\%20t\%C3\% AAm\%20carteira\%20assinada\&targetText=A\%20taxa\%20de\%20desemprego\%20no,quarta\%2Dfeir a\%20(31). Acesso em 18 de outubro 2019.

IANNI, Octavio (Org.). Florestan Fernandes: sociologia crítica e militante. São Paulo: Expressão Popular, 2. ed, 2011.

LEHER, Roberto. PAC, educação e heteronomia cultural. Revista de Políticas Públicas, v. 11, n. 1, pp. 9-33, 2007. Disponível em: http://www.redalyc.org/articulo.oa?id=321129121002. Acesso em 18 outubro 2019.

MATUI, Jiron. Cidadão e professor em Florestan. São Paulo, Cortez (Coleção Questões de nossa época, vol. 90), 2001.

OLIVEIRA, Marcos Marques de. Florestan Fernandes. Recife: Fundação Joaquim Nabuco/Editora Massangana, 2010. Disponível no portal MEC/Domínio Público/Coleção Educadores.

OLIVEIRA, Marcos Marques de. O articulista Florestan Fernandes: democracia e educação em tempos de neoliberalismo. In: FÁVERO, Osmar (Org.) Democracia e educação em Florestan Fernandes. Campinas, SP: Autores Associados; Niterói, RJ: Editora da Universidade Federal Fluminense (EdUFF), 2005.

PAULA, Maria de Fátima de. A perda da identidade e da autonomia da universidade brasileira no contexto do neoliberalismo. Avaliação: Revista da Avaliação da Educação Superior, v. 8, n. 4, 11, pp. 53-66, 2003. Disponível em

http://periodicos.uniso.br/ojs/index.php/avaliacao/article/view/1245/1235. Acesso em 11 abril 2020.

PARTIDO, Escola Sem. Projeto do Programa Escola Sem Partido. Site Escola Sem Partido. s/p, 2019. Disponível em: https://www.programaescolasempartido.org/projeto. Acesso em 24 agosto 2019.

SIRINELLI, Jean-François. Os intelectuais. In: REMOND, René (Org.). Por uma história política; tradução Dora Rocha. - Rio de Janeiro: FGV, 2. ed. 2003, pp. 231-269. 
RevistAleph 